\title{
Um Olhar Crítico-Reflexivo Sobre a Formação Continuada de Professores de Educação Física da Rede Municipal de Ensino de Santa Maria (RS) ${ }^{1}$
}

\author{
Ana Paula da Rosa Cristino* \\ Hugo Norberto Krug**
}

\begin{abstract}
Resumo: Este estudo teve como objetivo analisar os modelos de formação e as estratégias e/ou atividades institucionais e individuais a que estão submetidos os professores de Educação Física dos Anos Finais do Ensino Fundamental da rede municipal de ensino de Santa Maria (RS). A pesquisa qualitativa de enfoque fenomenológico possibilitou identificar as percepções dos professores sobre estes programas formação continuada. Partindo das necessidades da sociedade contemporânea, a intensificação e a continuidade dos estudos sobre estes programas é uma alternativa para o conhecimento do desenvolvimento profissional do professor e a valorização da escola.
\end{abstract}

Palavras-chave: Educação continuada. Educação Física Escolar. Desenvolvimento Profissional.

\section{Considerações InICIAIS SOBRE a ReALIZAÇÃo deste Estudo: OS Primeiros Olhares}

O contexto social mudou as expectativas com relação à escola, porém os professores, formadores e demais envolvidos no espaço educacional, ainda não conseguem reconhecer a essência dessa mudança, continuando a procura por uma ressiginficação coerente da educação. As estratégias e as concepções de formação continuada não vêm sendo entendidas adequadamente pelas instituições e professores.

1 Dissertação. Mestrado em Educação. PPGE/ CE/ UFSM.

* Mestre em Educação. Professora de Educação Física da rede pública de ensino de Santa Maria (RS). Grupo de Estudos e Pesquisa em Educação Física (GEPEF-UFSM), Santa Maria, RS. Brasil. E-mail: apcristino@pop.com.br

"* Doutor em Educação e Ciência do Movimento Humano (UFSM). Orientador. Professor do Departamento de Metodologia de Ensino e Programa de Pós-Graduação em Educação. Grupo de Estudos e Pesquisa em Educação Física (GEPEF-UFSM), Santa Maria, RS. Brasil. Email: hnkrug@bol.com.br 


\section{Artigos Originais Ana Paula Cristino e Hugo Norberto Krug}

Esta incompreensão compromete em parte a mudança das práticas pedagógicas, assim como a responsabilidade dos professores com os projetos das suas escolas.

A formação continuada para os docentes de Educação Física, e de outras áreas também, passa pela mesma angústia de verticalização dos modelos formativos, crise de identidade e dos saberes docentes na busca do seu espaço.

A compreensão inadequada compromete em parte a mudança das práticas pedagógicas, assim como a responsabilidade dos professores com os projetos das suas escolas. É preciso conhecer as estratégias e concepções vigentes para professores e suas instituições no sentido de repensar a identidade deste profissional, buscando uma formação continuada capaz de aproximá-los das reais necessidades da escola.

Partindo destas preocupações, esta pesquisa objetivou conhecer e analisar, pelo enfoque crítico-reflexivo, as concepções e as estratégias de formação continuada de professores de Educação Física dos anos finais do Ensino Fundamental da rede municipal de ensino de Santa Maria (RS).

\section{Encaminhamentos Metodológicos}

A investigação foi de caráter qualitativo, pois considerou as falas dos sujeitos e teve como opção metodológica a pesquisa de campo na modalidade exploratório-descritiva. Orientou-se no sentido de investigar a relação teoria-prática que deve configurar o fenômeno educativo comprometido com a transformação. Para Pádua (2004), a pesquisa qualitativa tem a preocupação com o significado dos fenômenos e processos sociais, levando em consideração as motivações, crenças, valores e representações sociais que permeiam a rede de relações na sociedade. Trata-se de descrever, antes de explicar e analisar, pois todo universo da ciência social é construído sobre o mundo vivido, buscando a fenomenologia colocar as idéias básicas e em seguida, esclarecê-las (TRIVIÑOS, 1987).

Os participantes desta pesquisa foram supervisores/ coordenadores pedagógicos e professores de Educação Física da rede

Movimento, Porto Alegre, v. 14, n. 01, p. 63-83, janeiro/abril de 2008. 
municipal de ensino de Santa Maria (RS), dos seguintes contextos escolares, de acordo com a região da cidade: central, periferia e rural. Também participaram professoras da SMEd - Secretaria de Município da Educação.

Primeiramente, realizou-se a análise documental para conhecerse os programas de formação continuada institucionais da rede municipal e dos Projetos Político-Pedagógicos das escolas. Para Pádua (2004) a pesquisa documental, tem sido largamente utilizada nas ciências sociais, na investigação histórica, a fim de descrever/comparar fatos sociais, estabelecendo suas características ou tendências.

Outra técnica utilizada foi a de entrevista semi-estruturada. Foi composta por questões referentes a concepção de formação continuada, estratégias de ação e repercussões esperadas na prática docente.

A interpretação utilizada foi análise de conteúdo. Para Triviños (1987), trata-se de um conjunto de técnicas de análise, visando inferir conhecimentos relacionados às condições de produção e recepção das mensagens por procedimentos sistemáticos e objetivos de descrição do conteúdo das mensagens,.

A partir da interpretação, as informações foram distribuídas em categorias de análise de acordo com os objetivos propostos para o estudo. Também com o andamento da análise das entrevistas e dos documentos, outras categorias surgiram, buscando definir as questões principais delimitadas para a pesquisa.

\section{INTERPRETAÇÃo dAs INFORMAÇõES: CONHECENDO o Diversos OLHARES}

\subsection{Os projetos político-pedagógicos (Ppps), o programa da rede Municipal e as expectativas textuais para a formação continuada}

Foi realizada uma compreensão crítico-reflexiva de como as escolas estudadas e a Secretaria Municipal de Educação (SMED) se relacionam com a formação de professores. Para responder a

Movimento, Porto Alegre, v. 14, n. 01, p. 63-83, janeiro/abril de 2008. 


\section{Artigos Originais Ana Paula Cristino e Hugo Norberto Krug}

tais questionamentos, foram utilizados os Projetos Político-pedagógicos (PPPs) e o texto-referência para a formação continuada da SMEd: o livro de orientações gerais sobre a Rede Nacional de Formação Continuada para professores de Educação Básica.

Como o enfoque tanto dos PPPs, quanto das orientações gerais da Secretaria de Educação Básica do Ministério de Educação (SEB) a educação é tratada como um todo, não apresentando divisões disciplinares. Por isso, a análise que vem a seguir também é ampla, tratando de reflexões sobre a educação e a formação continuada, sem entrar ainda na especificidade da Educação Física e se mantém fiel ao que está escrito nos textos lidos.

O parâmetro documental para o entendimento da formação permanente na rede municipal de ensino foi o livro de orientações gerais sobre a Rede Nacional de Formação Continuada para professores de Educação Básica, porque embora existisse previsão para a formação continuada nas ações de Governo Municipal e ela se efetivasse em várias atividades, no período de coleta de informações (2006), ainda não existia um texto ou documento que tratasse das questões sobre a formação de professores. Contudo, a equipe da SMED, comentou que o Plano Plurianual da Prefeitura Municipal de 2006 a 2008, contempla questões como: cursos de formação de professores em todas as áreas, cursos de atualização para os gestores, para os membros dos conselhos escolares e servidores, visando atingir 1.639 professores, 83 escolas, ao menos dois conselheiros de cada escola e 200 servidores. O texto ou programa de formação continuada da rede municipal elaborado pela SMEd, começou a ser escrito no início de 2007, fundamentando-se nas Orientações Gerais da SEB (BRASIL, 2005) e também nos relatos do $6^{\circ}$. Encontro Municipal de Educação Popular, da administração popular, cujo tema básico é "Educação Popular, compromisso de todos", onde diversos segmentos da educação participam de fóruns com espaço para debates.

Relatam-se a seguir informações sobre as três escolas estudadas:

Movimento, Porto Alegre, v. 14, n. 01, p. 63-83, janeiro/abril de 2008. 
1) Escola A: fundada em 1920, possui, portanto, 87 anos; situada na zona urbana (central) do município; conta com, aproximadamente, 800 alunos, 70 professores e seis funcionários;

2) Escola B: criada em 1995, tendo 12 anos; escola de periferia, busca atender a demanda de alunos para os ensinos diurno e noturno da região sul do município; em 2006 teve 878 alunos matriculados; conta com 73 professores e 5 funcionários;

3) Escola C: fundada há mais de 30 anos; situada na zona rural do município de Santa Maria (RS); atende cerca de 200 alunos da PréEscola e Ensino Fundamental completo; apresenta, em seu quadro funcional, 20 professores e três funcionários.

Os modelos de formação continuada, definidos por Demailly (1995), e a divisão estabelecida por Nóvoa (apud NASCIMENTO, 1999), permitem fazer-se relações com as propostas colocadas nos PPPs e orientações gerais da SEB.

A formação pode estimular o desenvolvimento profissional dos professores, tanto mais quando a escola possibilita sua autonomia no ambiente de trabalho. Segundo Nóvoa (1995), é importante valorizar paradigmas de formação que promovam a preparação de professores reflexivos, que assumam a responsabilidade do seu próprio desenvolvimento profissional e que participem como protagonistas na implementação de políticas educativas.

No entanto, parece que as propostas de formação continuada no Brasil ainda privilegiam a formação profissional desconhecendo, por vezes, a pessoa ou o cidadão em formação e suas biografias. Comumente, as estratégias privilegiam a formação técnica - treinamento com efeito multiplicador e/ ou vivências pontuais localizadas na socialização de experiências vividas.

Um programa de formação continuada se desenvolve em um espaço complexo e a escolha do melhor modelo ficará condicionada à união de forças desse espaço. Isso significa que um bom modelo para um grupo pode não o ser para outro, dependendo das expectativas e desejos dos participantes.

Movimento, Porto Alegre, v. 14, n. 01, p. 63-83, janeiro/abril de 2008. 


\section{Artigos Originais Ana Paula Cristino e Hugo Norberto Krug}

Embora as propostas tenham conteúdo relevante no sentido da preocupação social, coletiva, contextualizada da docência, é preciso buscar a superação e o protagonismo do professor e os seus porta-vozes, escutarem adequadamente os desejos de formação da categoria. Pois sabe-se das dificuldades de implementação das políticas de formação para os docentes em serviço, mesmo com o respaldo legal para a busca da qualificação.

É relevante debater a respeito dos programas ou modelos de formação continuada, porque implica em dar reconhecimento às agruras da prática pedagógica. $\mathrm{O}$ professor precisa ser assistido nos pontos nevrálgicos desta prática. A escola, o Estado, e o próprio professor não podem assistir a esta crescente generalização de crise no exercício da docência.

Como diz Demailly (1995), é preciso pensar em estratégias de formação continuada e processos de profissionalização implicando na desmistificação de conceitos. Os modelos de formação são referenciais teóricos, nunca existindo na sua forma pura, mas são importantes para apontar caminhos para formação docente.

De acordo com a análise dos textos, a utopia da maioria dos PPPs, demonstra ares da forma interativa reflexiva caracterizada por Demailly (1995), como uma aprendizagem da situação, com possibilidades para a ação e a busca de novas competências, sempre acompanhada de uma atividade reflexiva e teórica.

Enquanto na teoria percebe-se nuances da forma interativoreflexiva, na prática, na execução das estratégias de formação, nota-se muito a forma contratual que para Demailly (1995), caracteriza-se por uma relação simbólica do tipo contrato, entre os que promovem a formação e outras parcerias.

Também se observa a forma escolar com influência dos programas que ensinam saberes organizados pelo poder legítimo exterior aos professores, como por exemplo, a União, ao definir princípios e objetivos gerais para o encaminhamento das atividades de formação das escolas. Quando o Estado, Município ou a própria escola apresentam expectativas relacionadas aos índices de

Movimento, Porto Alegre, v. 14, n. 01, p. 63-83, janeiro/abril de 2008. 
aprovação, reprovação e evasão e interferem buscando os resultados desejados, fazendo por vezes, com que o sucesso do ensino seja evidenciado na qualidade dos produtos e na eficácia e economia de sua realização.

Comparando os textos com os dois grandes grupos de modelos comentados por Nóvoa (apud NASCIMENTO, 1999), para o qual o grupo de modelos estruturantes relaciona-se mais com a racionalidade técnica e o modelo construtivista, com a reflexão contextualizada, percebe-se a incidência dos dois grupos, porém com a essência da escrita freqüentemente voltada para a importância da reflexão no processo educativo.

Então, justamente como diz a literatura, as diferentes formas ou modelos, se manifestam com maior ou menor intensidade, simultaneamente, de acordo com as necessidades dos professores, suas intencionalidades e possibilidades de execução.

\subsection{A equipe diretiva, a SMED e os processos educativos: repercussões na formação continuada dos professores de Educação Física}

Considerando a influência da organização do trabalho pedagógico em toda a atividade escolar, esta análise buscou conhecer o posicionamento da supervisão/ coordenação pedagógica das escolas e da SMED sobre a formação continuada da rede municipal e as especificidades para os professores de Educação Física. Para tanto, participaram os supervisores das três escolas, uma professora da Assessoria de Projetos e outra da Direção de Ensino da SMED.

Quando se fala em mudança da prática de sala de aula, dificilmente a adesão é imediata. Por isso, a colaboração tanto da coordenação pedagógica das escolas quanto da SMED, consiste em proporcionar condições de trabalho e o comprometimento da sua concretização, articulando-se com os demais segmentos envolvidos. Porque na dificuldade da Secretaria dialogar pessoalmente com todos os professores da rede municipal de ensino, a coordenação pedagógica vem como mediadora das expectativas e necessidades do professorado.

Movimento, Porto Alegre, v. 14, n. 01, p. 63-83, janeiro/abril de 2008. 


\section{Artigos Originais Ana Paula Cristino e Hugo Norberto Krug}

Segundo Alarcão (2001), enquanto atribui-se aos professores a capacidade de serem atores sociais, responsáveis em sua autonomia, críticos em seu pensamento, solicita-se para a equipe diretiva a capacidade de liderança mobilizadora de vontades e idéias partilhadas com a efetiva gestão de serviços e recursos.

De acordo com as professoras entrevistadas da SMED, a rede possui um intenso programa de formação em todas as áreas do Ensino Fundamental. Nos últimos tempos, tem se constituído principalmente da questão curricular, tendo como foco principal o envolvimento com as funções da aprendizagem no ano de 2006, com o trabalho realizado em todas as áreas voltado para essa temática. Este trabalho diz respeito tanto ao incentivo da formação docente realizada nas próprias escolas, como outras promovidas pela Secretaria, que trabalham com toda a rede ou grupos separadamente: equipe diretiva, professores, funcionários.

Geralmente o trabalho de formação docente é desenvolvido em pequenos grupos, porque a rede municipal é grande. As formações gerais ocorrem com palestras, cursos mais intensivos de $20 \mathrm{e}$ 40 horas, mini-cursos, oficinas.

A Secretaria também vem discutindo a importância de enfatizar a formação que ocorre na própria escola. Segundo Alarcão (2001), quando a escola passa a assumir sua formação, também se responsabiliza, junto com os professores e alunos, à instituição de ações concretas, encaminhando a reflexão sobre novas configurações organizativas do cotidiano da escola, tornando-a uma organização aprendente, com desenvolvimento para si mesma e para cada um dos que a constituírem.

Sobre a Educação Física, as professoras-colaboradoras da Secretaria comentaram que o trabalho é consolidado na rede, embora tenha diversificação de enfoques, indo do tecnicismo até a perspectiva integral. Para a SMED, espera-se que a disciplina encaminhe cada vez mais as atividades para os pressupostos da Educação Popular.

Segundo Oliveira (2007), pensar a importância da Educação Física Escolar no sistema educacional está cada vez mais

Movimento, Porto Alegre, v. 14, n. 01, p. 63-83, janeiro/abril de 2008. 
importante. Por isso torna-se fundamental que o professor tenha o apoio e acompanhamento necessários dentro da organização escolar para refletir sobre suas práticas pedagógicas.

Quanto à formação de professores de Educação Física, é preciso responder, de forma precisa e inequívoca, a questões como:

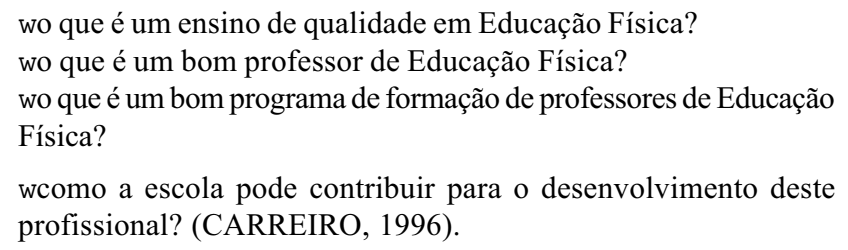

Para as supervisoras pedagógicas que são as mediadoras entre a Secretaria e os professores, quando questionadas sobre o trabalho da Educação Física Escolar, tiveram respostas variadas. As Supervisoras das Escolas A e B, comentaram não terem muito conhecimento das especificidades trabalhadas na disciplina. A Supervisora da Escola $C$, falou que acompanha e sabe do andamento das atividades desenvolvidas na Educação Física.

Incansavelmente é tema de debate a importância do trabalho em equipe, da reflexão, e de recursos adequados para um exercício adequado da docência. Mas, é fato que muitos professores de Educação Física não são devidamente assessorados em suas atividades. Será que efetivamente ocorre esse apoio às atividades do professor de sala de aula, em especial aqui, ao de Educação Física? É preocupante que em duas das escolas estudadas, os supervisores não conheçam o trabalho de seus professores. Embora esse aspecto não possa ser generalizado, porque existem alguns professores com o devido apoio à sua prática pedagógica, muitos outros não possuem o acompanhamento necessário.

Por isso algumas especificidades, como o currículo e a avaliação na Educação Física ainda estão em aberto. Trabalhar estas questões envolveria tanto a tomada de novas posturas por um grupo considerável de seus professores, assim como esperar um conhecimento maior de outros profissionais sobre a importância e os fundamentos

Movimento, Porto Alegre, v. 14, n. 01, p. 63-83, janeiro/abril de 2008. 


\section{Artigos Originais Ana Paula Cristino e Hugo Norberto Krug}

da disciplina. E em meio a essas buscas, a Educação Física continua tendo diversificação de enfoques e apoio pouco adequado de uma parte significativa dos supervisores pedagógicos que atuam nas escolas.

Comparando as estratégias e concepções de formação relatadas pelas Escolas e a SMED com os modelos descritos por Pérez Gómez (2000), nas falas, as atividades se encaminham para a perspectiva da reflexão na prática para a reconstrução social e a perspectiva prática com enfoque reflexivo sobre a prática. Nesse enfoque, o professor precisa tornar-se investigador da sua aula (STENHOUSE apud PÉREZ GÓMEZ, 2000).

$\mathrm{Na}$ efetivação das estratégias de formação, o estilo de formação oferecida pela SMED, caracterizada fortemente por cursos e seminários, atualiza de certa forma o professor, ou seja, informa, mas não forma, não possibilitando um adequado espaço para a reflexão. Este fato vai de encontro ao constatado por Molina Neto (1997), sobre as formações que mais comumente participam os professores. As atividades direcionadas à reflexão e à produção de conhecimento têm espaços reduzidos nos encontros. Também as escolas se enquadram nessa perspectiva, devido ao fato da extrapolada carga horária dos professores em virtude das constantes reestruturações de pessoal, aumentando turmas sem o aumento igual de professores, inversamente, diminuindo os espaços para encontros e reuniões, ou seja, redução no espaço para a reflexão.

Os comentários das supervisoras das Escolas e das professoras da Secretaria com relação a prática pedagógica da Educação Física e suas necessidades formativas, se aproximam da perspectiva prática com enfoque tradicional. Nesse modelo a cultura profissional e $o$ conhecimento são produtos da adaptação às exigências do contexto sobre a escola. Também situam a disciplina na perspectiva técnica de Pérez Gómez (2000).

Percebe-se então, diferenças entre os discursos das escolas e da Secretaria e as possibilidades de concretização de metas educacionais mais ousadas. A intenção não é indicar culpados, mas perceber como a inovação educacional esbarra em dificuldades

Movimento, Porto Alegre, v. 14, n. 01, p. 63-83, janeiro/abril de 2008. 
estruturais. A transformação da escola e da estrutura educacional em reflexiva e emancipadora é uma construção, que exige romper com a ordem estabelecida. Por isso, realizar esta organização é acreditar na possibilidade da mudança como resultado do esforço contínuo, científico, ético, solidário, coletivo (ALARCÃO, 2001).

É indispensável a interação entre professores, gestores e autoridades intermediárias, somando esforços para pensar a formação continuada como algo realmente indispensável e viável nas possibilidades de valorizar cada realidade e enfrentar os desafios educacionais.

\subsection{Os professores de Educação Física e a formação continuada: perspectivas e desafios}

Pensando nas concepções de formação continuada, estratégias de ação, prática pedagógica, relações na escola e com a Mantenedora, os professores desta pesquisa falaram sobre as perspectivas e desafios presentes no cotidiano da Educação Física dos Anos Finais do Ensino Fundamental. Participaram do estudo, 5 professores das escolas pesquisadas:

Da Escola A, uma professora formada há 12 anos, com 6 anos de atividade na rede, 20 horas em 1 escola e 20 horas em academia, sem curso de pós-graduação, que atende turmas de Anos Finais do Ensino Fundamental. A outra professora, formada há 23 anos, 18 anos de serviço, 40 horas semanais na rede pública em 1 escola e 15 na rede particular de ensino, com Especialização em Interdisciplinaridade. Trabalha em turmas de Anos Iniciais, Finais e EJA.

Os professores da Escola B, o primeiro com 25 anos de docência, concluiu seu curso de graduação há 26 anos, sem curso de pós-graduação e 20 horas de serviço em 1 escola, atendendo turmas de Anos Finais. Também trabalha com treinamento de equipes de futsal para torneios escolares. A segunda professora com 6 anos de atuação, 30 horas em 2 escolas municipais e 15 horas como personal trainer, formada há 22 anos, com Curso de Especialização em Ciência do Movimento Humano. Atualmente está com turmas de Anos Iniciais e Finais.

Movimento, Porto Alegre, v. 14, n. 01, p. 63-83, janeiro/abril de 2008. 


\section{Artigos Originais Ana Paula Cristino e Hugo Norberto Krug}

A professora da Escola C, com 14 anos de serviço e 40 horas de trabalho no município em 2 escolas, formada há 17 anos, com Especialização em Educação Ambiental. Trabalha com turmas de Anos Finais. Possui um projeto que desenvolve em suas aulas na escola rural, sobre construção de jogos a partir das modalidades esportivas oficiais.

Para eles, cursos, leituras, novas idéias e a fundamentação teórica do trabalho estão relacionados com a formação continuada, que pode ser oferecida tanto na escola, quanto fora dela. Conforme Onofre (1996), atribuir à formação de professores um caráter contínuo e sistemático significa aceitar que esta acontece, com freqüência e regularmente, desde as primeiras experiências ainda como candidato a professor, se encaminhando para toda a vida profissional.

Para três professores deste estudo, seria importante que as formações em Educação Física contemplassem questões relacionadas ao esporte. Já outros dois, pensam em uma formação continuada como espaço de trocas e sempre relacionada não com conteúdos específicos, mas com as necessidades educativas dos alunos.

As falas dos professores dizem respeito a duas questões importantes: primeiramente que o cotidiano das aulas de Educação Física demonstra o vínculo forte com a esportivização. Günther (2000), nesse sentido, afirma que o esporte é conteúdo hegemônico na Educação Física Escolar. Embora não sejam trabalhados os modelos tais quais os dos esportes de rendimento, as formas de jogo abordadas seguem os moldes do esporte tradicional com uma flexibilidade das regras, conforme o nível de possibilidades de cada grupo.

Também, que a participação em um grupo de discussão ou análise das práticas, pode servir de iniciação para uma prática reflexiva pessoal. Essa questão é importante, porque em algumas fases da vida profissional, a reflexão solitária ou inserida nas estruturas comuns de trabalho, não permite avanços, a participação em um grupo de trocas ou análise pode oferecer apoio (PERRENOUD, 2002).

Movimento, Porto Alegre, v. 14, n. 01, p. 63-83, janeiro/abril de 2008. 
Devido ao caráter altamente contextualizado e complexo da atividade profissional do professor, a análise casuística de episódios reais apresenta-se como uma estratégia de grande valor formativo, pois permite revelar situações complexas e construir conhecimento ou tomar consciência do que afinal já sabia (ALARCÃO, 2003).

Segundo Krug (2001), os comentários e discussões dos professores sobre um determinado caso, contribuem para análise de situações e o estudo de alternativas para se colocar em ação. Em um estudo sobre rede de auto-formação participada com vistas ao desenvolvimento profissional, este autor percebeu que até colaborações simples, como por exemplo, o compartilhar impressões e análises de situações de sala de aula com os colegas, contribuem, pois a capacidade de reflexão de cada um passa a ser importante ingrediente da análise coletiva do andamento do grupo e um dos principais trunfos no ajuste das relações profissionais da equipe.

Dentre os espaços oferecidos para a formação nas escolas, foram colocadas as reuniões pedagógicas. Para estes professores, as reuniões transitam entre as questões burocráticas e administrativas. Em função do pouco tempo, falta um espaço maior para o pedagógico e o conhecimento compartilhado. Enquanto alguns dos colaboradores participam ativamente das pautas, outros disseram serem mais ouvintes neste importante espaço formativo.

Esta questão revela dois lados: um que é do comprometimento que o professor tem na participação deste espaço, e outro é se realmente as reuniões pedagógicas oferecem oportunidades formativas, ou assumem constantemente a rotina de avisos gerais, e a tomada de soluções emergenciais para os problemas que ocorrem na escola.

Para Tavares (2001), uma escola reflexiva deverá ser antes de tudo, uma escola de pessoas que pensam, sentem, sofrem, vivem, agem, colaboram entre si: a escola dos professores e demais agentes educativos. Todos deveriam ser essencialmente reflexivos, com um verdadeiro conhecimento e sentimento de si e dos outros.

No entanto, parece ás vezes, que a estrutura dos espaços, desencoraja um conhecimento profissional partilhado dos professores,

Movimento, Porto Alegre, v. 14, n. 01, p. 63-83, janeiro/abril de 2008. 


\section{Artigos Originais Ana Paula Cristino e Hugo Norberto Krug}

dificultando o investimento das experiências significativas nos percursos de formação e a sua formulação teórica (NÓVOA, 1991).

Todos eles alegam que a falta de tempo é um dos grandes empecilhos ao engajamento em mais atividades de formação continuada. Com o preenchimento quase total das cargas horárias e o atendimento a um grande número de turmas, fica difícil dispensar os alunos a cada formação que surge.

A carga de trabalho dos professores segundo Tardif, Lessard e Lahaye (1991), é um problema administrativo, definida em duração pela organização escolar em função das normas oficiais, encaminhadas pelo governo. O tempo de trabalho diário, semanal, anual, o número de horas de presença obrigatória em classe, o número de alunos, $\mathrm{o}$ salário, definem o quadro legal no qual o ensino se desenvolve.

Assim como estes professores deixam clara a dificuldade de fazer sempre as atividades de formação continuada, especialmente aquelas que ocorrem fora da escola, também colocam os critérios para a escolha das formações que participam. Eles procuram a formação de acordo com a necessidade, ou seja, se os conhecimentos abordados poderão colaborar na prática, e como a Educação Física é ampla, as possibilidades são bastante variadas. Um critério importante é se o curso é prático, porém são conscientes da importância das abordagens teóricas.

A questão da existência de atividades de formação geral e poucas atividades na área específica, para esses professores é um espaço perdido do desenvolvimento profissional. Günther (2000) comenta essa mesma percepção nos professores de Educação Física. A mudança é vista como necessária, mas a existência de mais formações específicas não pode ser deixada de lado.

Os professores de Educação Física falaram sobre a repercussão das atividades formativas na sua atuação em sala de aula. Alguns desses professores observaram grandes mudanças, outros algumas, e também existiu professor que notasse praticamente nenhuma contribuição.

Movimento, Porto Alegre, v. 14, n. 01, p. 63-83, janeiro/abril de 2008. 
Então, há necessidade de autonomia para intervir em muitos dos problemas existentes nas políticas de formação de professores. Para Giroux (1997), estas atividades são fortemente influenciadas por uma teoria educacional que tem sido construída em torno de um discurso e conjunto de práticas que enfatizam aspectos metodológicos imediatos e mensuráveis da aprendizagem.

Segundo Porto (2000), a realidade educativa não pode ser enquadrada em esquemas preestabelecidos, a formação e a prática pedagógica não se reduzem à mera instrumentalização ou à "acertada" escolha de meios e de procedimentos. A formação/ prática pedagógica precisam ser vistas como situações problemáticas, contextualizadas, únicas.

Os modelos e a forma como o professor e a escola conduzem o desenvolvimento profissional, dão respostas para algumas indagações prévias relativas à formação, concepção de professor, assim como a algumas teorias sobre as estratégias mais adequadas para facilitar a sua aprendizagem (GARCÍA, 1999).

As atividades e estratégias, que caracterizam-se por cursos e seminários mais comumente, são intensivas e sugerem propostas pedagógicas que nem sempre se assemelham às condições que os professores vivenciam. $\mathrm{O}$ trabalho reflexivo nestas estratégias, muitas vezes reside na contextualização destas propostas, no entanto com pouco espaço para o debate no grupo. As estratégias de formação mais comuns são os cursos, seminários e leituras individuais, que relacionam-se a perspectiva técnica e prática colocadas por Pérez Gómez (2000).

Perspectivas como a de reflexão e reconstrução social, ainda estão afastadas do cotidiano pedagógico dos mesmos, ao argumentarem que a inovação e a transformação, freqüentemente esbarram no excesso de carga horária, pouco material e falta de espaço físico adequado.

As escolas tentam oferecer espaço para seus atores, inclusive com a perspectiva reflexiva, sendo contemplada no texto de seus projetos educativos. A realidade do cotidiano escolar, é uma instância

Movimento, Porto Alegre, v. 14, n. 01, p. 63-83, janeiro/abril de 2008. 


\section{Artigos Originais Ana Paula Cristino e Hugo Norberto Krug}

privilegiada para a formação do professor em serviço, desde que existam condições gerais básicas para um adequado trabalho pedagógico.

Todas as problemáticas aqui comentadas demonstram a necessidade de se produzirem mudanças na prática de professores, nas escolas e Secretarias de Educação, de forma mais eficaz buscando novos caminhos para o desenvolvimento profissional. A abordagem crítico-reflexiva é uma importante oportunidade para se consolidar o reconhecimento da importância do professor e seu processo de profissionalização como variável decisiva para a compreensão do fenômeno educativo. A integração entre as práticas pedagógicas, os conhecimentos teóricos e a reflexão são capazes de constituir atividades docentes mais coerentes e críticas, preocupadas em consolidar o processo contínuo de formação da identidade profissional.

\section{Considerações Finais: Possibilidades de Novos Olhares}

Os resultados demonstraram que os planejamentos institucionais embora sistemáticos, não atendem satisfatoriamente às necessidades do desenvolvimento profissional dos professores da rede. Além da contribuição dos cursos e seminários ser pequena, a prática pedagógica sofre pouca influência destas estratégias, que são caracterizadas pelos moldes da racionalidade técnica.

Entre as iniciativas individuais ou informais, os professores colocam a troca de experiências, que é o fator que mais contribui para a transformação da prática pedagógica. Muitos deles falam da necessidade de sistematizar o espaço para a partilha de experiências e saberes da profissão como estratégia formativa.

Percebe-se que textualmente tanto os modelos quantos as estratégias individuais e institucionais são reflexivas e emancipatórias. No entanto, nota-se também uma dificuldade em efetivar tais estratégias. É preciso buscar alternativas, dentro das possibilidades que a rede municipal de ensino e as escolas possuem, para promover um desenvolvimento profissional mais autônomo e reflexivo.

Movimento, Porto Alegre, v. 14, n. 01, p. 63-83, janeiro/abril de 2008. 
Os professores de Educação Física deste estudo, quando se referiram às estratégias individuais, concentraram-se significativamente nos modelos técnico e prático (PÉREZ GÓMEZ, 2000). Para que sejam refletidas as percepções sobre os modelos e estratégias de ação vigentes e proporcionados encaminhamentos, é preciso ser produzido um espaço para se pensar nos pressupostos pedagógicos e formativos que existem e aqueles que têm intencionalidade de surgirem.

A formação continuada nas perspectivas colocadas por Alarcão (2001); García (1999); Krug (2004), que vão de encontro às propostas deste estudo, necessitaria contemplar um programa que incluísse todo um conjunto de recursos diversos - não apenas cursos, seminários, simpósios, congressos, mesas-redondas, encontros, conferências, oficinas, mas também, trabalho pedagógico coletivo, estudos individuais - de maneira concatenada e ao longo da vida profissional.

Também há a necessidade de se romper com a concepção da escola "apenas" como um espaço para se ensinar. Temos que passar a perceber esse espaço como local de produção de conhecimentos e saberes.

A área da Educação Física Escolar, necessita de constantes estudos que abordem as questões entre a formação e a constituição docente do professorado, já que a compreensão e a solução dos problemas formativos é um dos obstáculos para a superação da dicotomia teoria-prática, fato que indica serem cada vez mais necessárias pesquisas que analisem de forma sistematizada quais os pressupostos teóricos-filosóficos que vêm orientando o processo de formação dos profissionais desta área de conhecimento. Também necessita de pesquisas que avaliem os programas de formação continuada de professores, de iniciativa das redes públicas de ensino. Por outro lado, novas formas de conceber a escola, são uma via para pensar a formação continuada.

A formação continuada não é a única responsável pela melhoria da qualidade de ensino, porém partindo das necessidades da

Movimento, Porto Alegre, v. 14, n. 01, p. 63-83, janeiro/abril de 2008. 


\section{Artigos Originais Ana Paula Cristino e Hugo Norberto Krug}

sociedade contemporânea, a intensificação e a continuidade dos estudos sobre sua atividade e das suas relações com as biografias de cada ator é o que torna o professor, conhecedor da sua profissão.

Movimento, Porto Alegre, v. 14, n. 01, p. 63-83, janeiro/abril de 2008. 


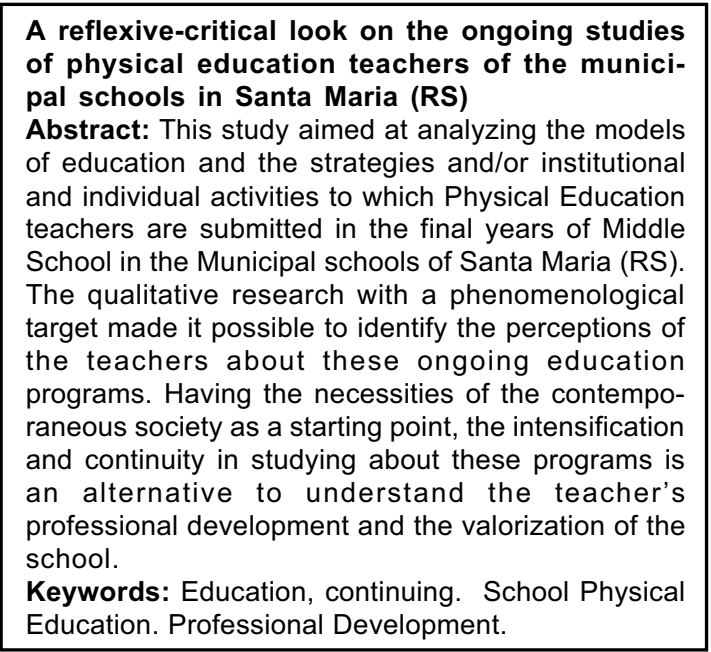

Una mirada crítico-reflexiva sobre el perfeccionamiento de profesores de Educación Física de la Red Municipal de Enseñanza de Santa Maria (RS)

Resumen: Este estudio tiene como objetivo analisar los modelos de formación y las estrategias y/o actividades institucionales a que están sometidos los profesionales del área de Educación Física del segundo ciclo de Ensenãnza Primaria de la red pública municipal de Santa Maria (RS). La investigación calitativa de enfoque fenomenológico propuso identificar las percepciones de los profesores sobre estos programas de perfeccionamiento. Se tiene como base las necesidades de la sociedad contemporanea, la intensificación y la continuidad de los estudios sobre tales programas es una posibilidad para el conocimiento del desarrollo profesional del profesor y la valoración de la escuela.

Palabras-clave: Educación continua. Profesores, Educación Física Escolar. Desarrollo Profesional.

\section{REFERÊNCIAS}

ALARCÃO, I. Professores reflexivos em uma escola reflexiva. São Paulo: Cortez, 2003.

Movimento, Porto Alegre, v. 14, n. 01, p. 63-83, janeiro/abril de 2008. 


\section{Artigos Originais Ana Paula Cristino e Hugo Norberto Krug}

A escola reflexiva. In: ALARCÃO, I. (Org.). Escola reflexiva e nova racionalidade. Porto Alegre: Artmed, 2001. p.15-30.

BRASIL. Orientações gerais: Rede Nacional de Formação Continuada de professores de Educação Básica. Brasília: MEC/ SEB, 2005.

CARREIRO DA COSTA, F. Formação de professores: objetivos, conteúdos e estratégias. In: CARREIRO DA COSTA, F. et al. Formação de professores em Educação Física: concepções, investigação, prática. Lisboa: Faculdade de Motricidade Humana, 1996. p. 9-36.

DEMAILLY, L.C. Modelos de formação contínua e estratégias de mudança. In: NÓVOA, A. (Org.) Os professores e a sua formação. Lisboa: Dom Quixote, 1995. p. 139-156.

GARCÍA, C.M. Desenvolvimento profissional dos Professores. In: Formação de professores: para uma mudança educativa. Lisboa: Porto Editora, 1999. p.133-258.

GIROUX, H.A. Professores como intelectuais transformadores. In:_. Os professores como intelectuais: rumo a uma pedagogia crítica da aprendizagem. Porto Alegre: Artes Médicas, 1997. p.157-177.

GÜNTHER, M.C.C. Formação permanente de professores de Educação Física na rede municipal de ensino de Porto Alegre no período de 1989 a 1999 - um estudo a partir de quatro escolas da rede. 2000. 204 f. Dissertação. (Mestrado em Ciências do Movimento Humano) - Universidade Federal do Rio Grande do Sul, Porto Alegre, 2000.

KRUG, H.N. Rede de auto-formação participada como forma de desenvolvimento do profissional de Educação Física, 2004. 220 f. Tese (Doutorado em Ciência do Movimento Humano) - Universidade Federal de Santa Maria, Santa Maria, 2004

A construção do conhecimento prático do professor de Educação Física. 2001. 254 f. Tese (Doutorado em Educação) - Universidade Federal de Santa Maria, Santa Maria, 2001

MOLINANETO, V. A formação profissional em Educação Física e esportes. Revista Brasileira de Ciências do Esporte, Maringá, v. 19, n.1, p. 34-41, 1997.

NASCIMENTO, M. das G. A formação continuada dos professores: modelos, dimensões e problemática. In: CANDAU, V.M.F. (Org.). Magistério: construção cotidiana. 3 ed. Rio de Janeiro: Vozes, 1999. p. 69-90.

NÓVOA, A. A formação contínua entre a pessoa-professor e a organizaçãoescola. Revista Inovação, Lisboa, n.1, p. 63-77, 1991

Formação de professores e profissão docente. In: NÓVOA, A. (Org.) Os professores e a sua formação. Lisboa: Dom Quixote, 1995. p. 15-34.

Movimento, Porto Alegre, v. 14, n. 01, p. 63-83, janeiro/abril de 2008. 
OLIVEIRA, A. A. B. de. Educação Física Escolar: a necessidade de novos olhares. Uniandrade:Revista Eletrônica de Educação Física, Curitiba, v.1, n.1, 2002. Disponível em: <http://www.uniandrade.br>. Acesso em: 18 jan. 2007.

ONOFRE, M.S. A supervisão pedagógica no contexto da formação didática em Educação Física. In: CARREIRO DA COSTA, F. et al. Formação de professores em Educação Física: concepções, investigação, prática. Lisboa: Faculdade de Motricidade Humana, 1996. p.75-118.

PÁDUA, E.M.M. de. Metodologia da pesquisa: abordagem teórico-prática. 10. ed. São Paulo: Papirus, 2004.

PÉREZ GÓMEZ, A.I. A função e formação do professor/a no ensino para a compreensão: diferentes perspectivas. In: SACRISTÁN, J.G.; PÉREZ GÓMEZ, A.I. Compreender e transformar o ensino. 4. ed. Porto Alegre: Artmed, 2000. p. 353-379.

PERRENOUD, P. Prática reflexiva e envolvimento crítico. In A prática reflexiva no ofício de professor: profissionalização e razão pedagógica. Porto Alegre: Artmed, 2002. p. 189-210.

PORTO, Y. da S. Formação continuada: a prática pedagógica recorrente. In: MARINA, J. (org.) Educação continuada: reflexões, alternativas. Campinas: Papirus, 2000. p. 11-38.

TARDIF, M.; LESSARD, C.; LAHAYE, L. Os professores face ao saber: esboço de uma problemática do saber docente. Teoria e Educação, Porto Alegre, n.4, p.215-233, 1991.

TAVARES, J. Relações interpessoais em uma escola reflexiva. In: ALARCÃO, I. (Org.). Escola reflexiva e nova racionalidade. Porto Alegre: Artmed, 2001. p. 31-64.

TRIVIÑOS, A.N. S. Introdução à pesquisa em ciências sociais: a pesquisa qualitativa em educação. São Paulo: Atlas, 1987.

Movimento, Porto Alegre, v. 14, n. 01, p. 63-83, janeiro/abril de 2008. 